\title{
Intraductal radiofrequency ablation of an intraductal papillary mucinous neoplasia of the main pancreatic duct
}

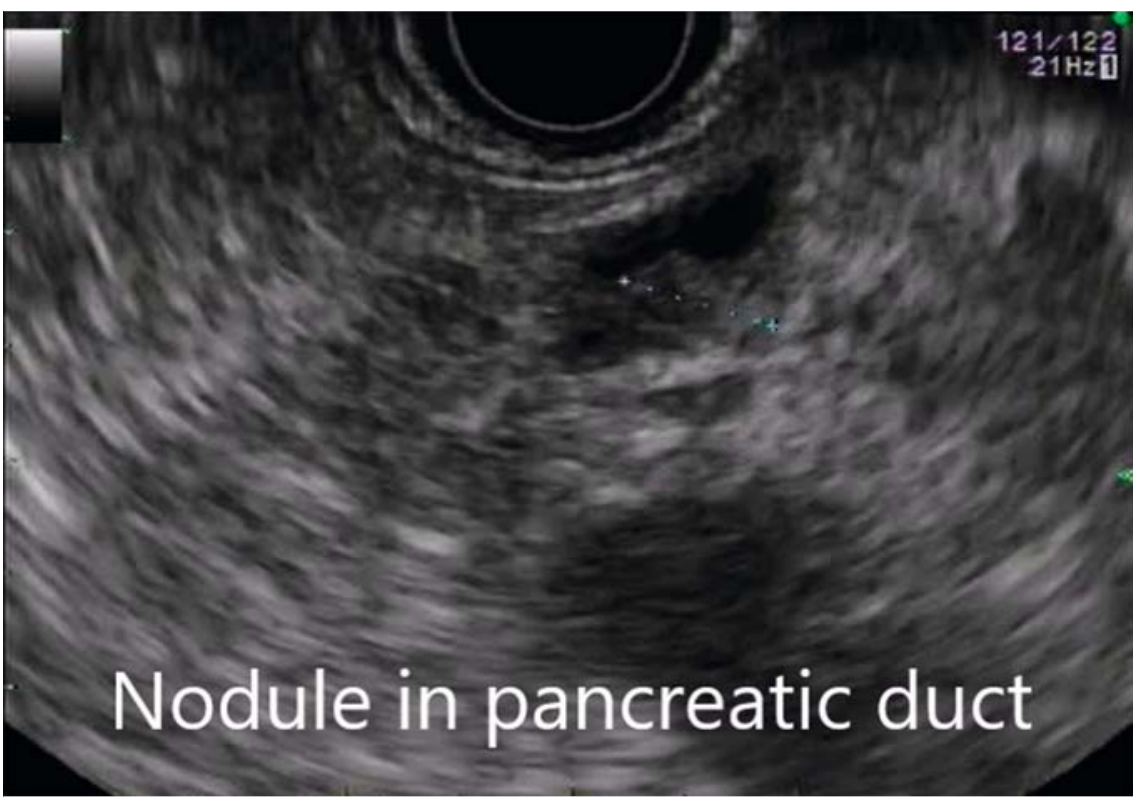

- Fig. 1 Endoscopic ultrasonography view of a tissue nodule protruding into the main pancreatic duct.

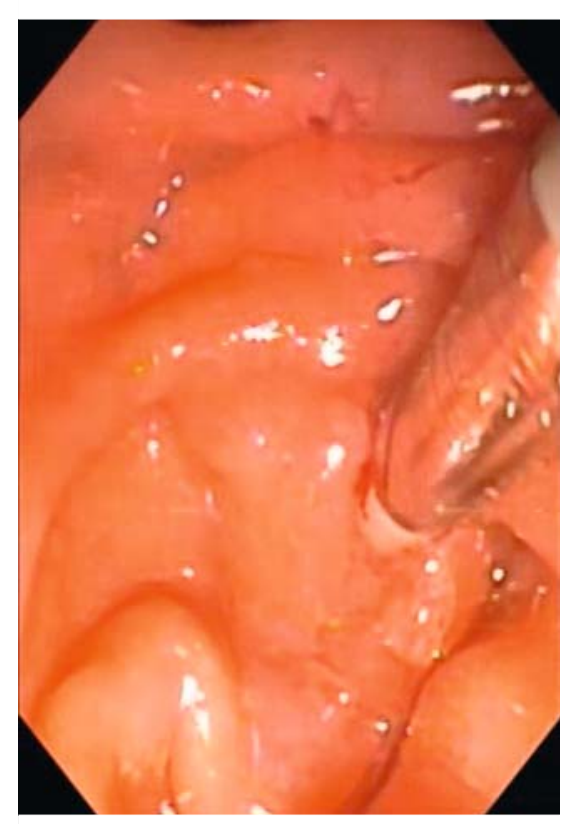

Fig. 3 Endoscopic view showing insertion of the EndoHPB radiofrequency ablation probe through the minor papilla.

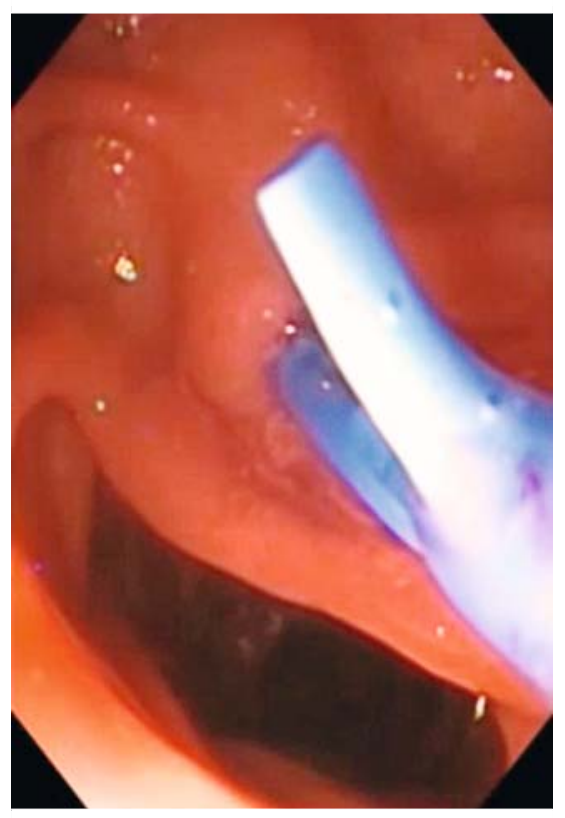

Fig. 4 Endoscopic view showing temporary placement of a 7-Fr pancreatic stent after radiofrequency ablation had been performed.

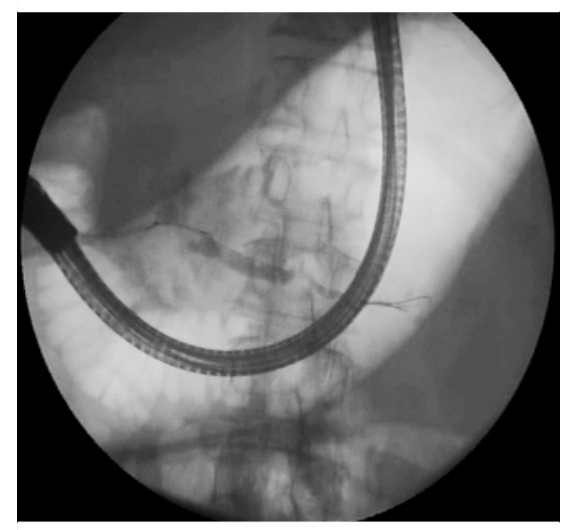

- Fig. 2 Endoscopic retrograde cholangiopancreatography view of a small pancreatic duct stricture with upstream pancreatic duct dilatation.

An 82-year-old man was referred for exploration and treatment of a stenosis of the main pancreatic duct that was found incidentally during a computed tomography (CT) scan. He reported no symptoms.

Endoscopic ultrasonography (EUS) showed an 8-mm intraductal nodule in the pancreatic isthmus ( Fig.1), with upstream dilatation of the main pancreatic duct, a pancreas divisum, and a gaping minor papilla. Endoscopic retrograde cholangiopancreatography (ERCP)-guided brush cytology and EUS-guided biopsy found an intraductal papillary mucinous neoplasia (IPMN) with dysplasia (ฉ Fig.2). Sphincterotomy was performed and a 7-Fr plastic stent was inserted through the minor papilla.

Pancreatic resection was deemed inadvisable given the patient's age and comorbid conditions. After multidisciplinary team discussion, intraductal radiofrequency ablation (RFA) was offered 2 months later ( $\triangleright$ Video 1$)$.

A Habib endo-HPB RFA probe (EMcision Ltd, London, UK) was inserted into the dorsal pancreatic duct over a guidewire ( Fig.3) with the two electrodes straddling the mural nodule. RFA was applied for 60 seconds (power $10 \mathrm{~W}$, effect 8 ) 


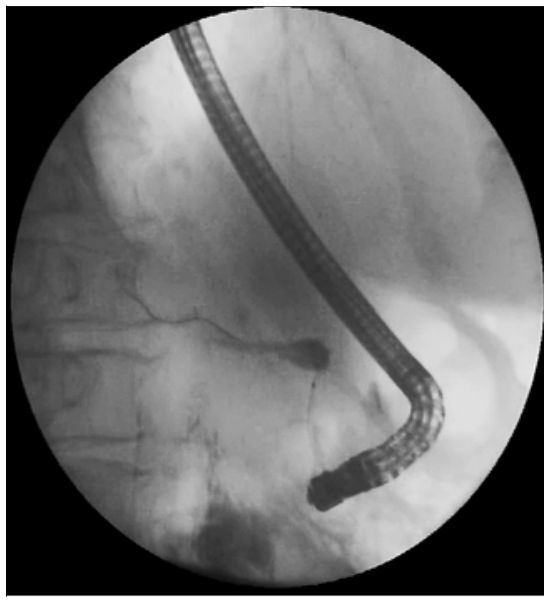

- Fig. 5 Image during follow-up endoscopic retrograde cholangiopancreatography 3 months later showing no residual stricture after stent removal.

using a VIO 300 D surgical unit (Erbe Medizin, Tübingen, Germany). A new 7- $\mathrm{Fr}$ stent was placed to prevent secondary stenosis ( $\triangleright$ Fig.4). No adverse events occurred.

Follow-up ERCP and EUS 3 months after the RFA showed no evidence of a residual nodule. Brush cytology found normal pancreatic ductal epithelium and ERCP demonstrated free pancreatic drainage ( Fig.5).

RFA removes neoplastic tissue via coagulative necrosis [1]. Experience of pancreatic RFA is scarce owing to the fear of serious adverse events and the fact that endoscopic biliopancreatic RFA devices have only recently become available [1]. Only a few animal studies and small clinical series [1-5], which included one case of IPMN ablation [2], have been reported, and all of these used EUS guidance. The present case is the first to report the use of an intraductal RFA catheter that was initially developed for biliary ablation [1]. The effective outcome and uneventful recovery suggest this technique could be offered with a curative intent in selected patients.

Endoscopy_UCTN_Code_TTT_1AR_2AF

\section{Competing interests}

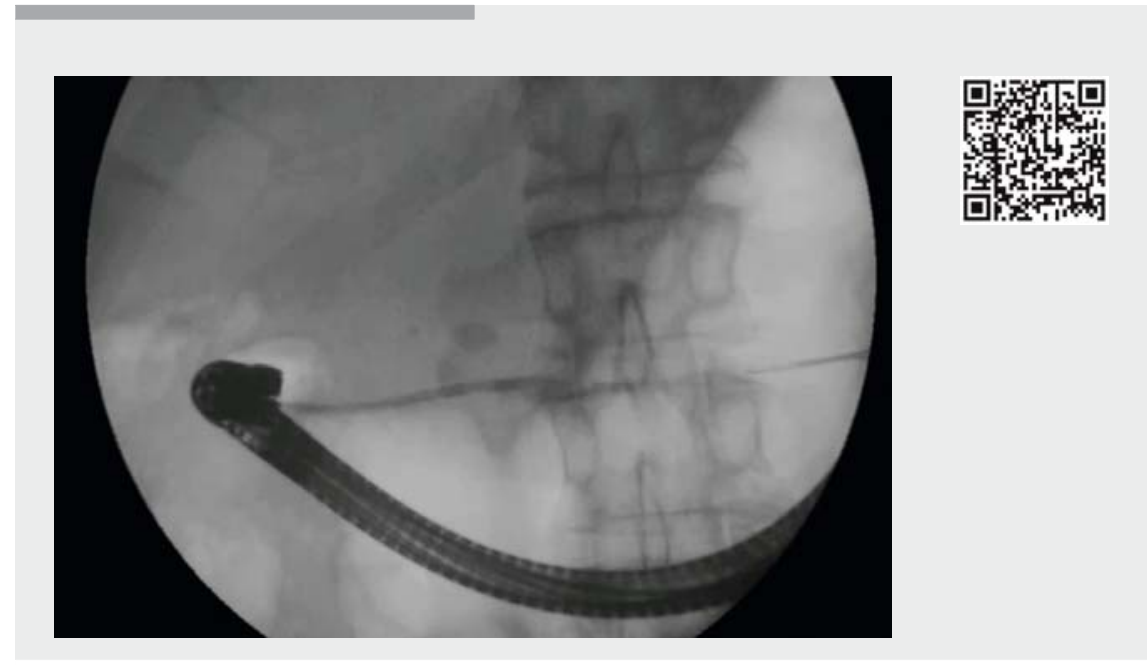

$\checkmark$ Video 1 Intraductal radiofrequency ablation (RFA) of an intraductal papillary mucinous neoplasia of the main pancreatic duct: endoscopic ultrasonography (EUS) and endoscopic retrograde cholangiopancreatography (ERCP) appearances before RFA; the RFA procedure using the EndoHPB intraductal probe; follow-up ERCP and EUS 3 months later.

The authors

Diane Lorenzo' ${ }^{1}$, Maximilien Barret ${ }^{1}$, Benoit Bordacahar ${ }^{1}$, Sarah Leblanc ${ }^{1}$, Stanislas Chaussade ${ }^{1}$, Pierre Cattan ${ }^{2}$, Frédéric Prat ${ }^{1}$

1 Service de Gastroentérologie, Hôpital Cochin, Paris, France

2 Service de Chirurgie digestive, Hôpital Saint Louis, Paris, France

\section{Corresponding author}

\section{Diane Lorenzo, MD}

27 Rue du Faubourg Saint-Jacques, 75014

Paris, France

diane.Iorenzo@gmail.com

Fax: +33-1-58411965

\section{References}

[1] Rustagi T, Chhoda A. Endoscopic radiofrequency ablation of the pancreas. Dig Dis Sci 2017; 62: 843-850

[2] Pai M, Habib N, Senturk H et al. Endoscopic ultrasound guided radiofrequency ablation, for pancreatic cystic neoplasms and neuroendocrine tumors. World J Gastrointest Surg 2015; 7: $52-59$

[3] Park J-S, Seo D-W, Song T] et al. Endoscopic ultrasound-guided ablation of branch-duct intraductal papillary mucinous neoplasms: Feasibility and safety tests using porcine gallbladders. Dig Endosc 2016; 28: 599 606
[4] Carrara S, Arcidiacono PG, Albarello L et al. Endoscopic ultrasound-guided application of a new internally gas-cooled radiofrequency ablation probe in the liver and spleen of an animal model: a preliminary study. Endoscopy 2008; 40: 759-763

[5] Brown NG, Camilo J, McCarter M et al. Refractory jaundice from intraductal papillary mucinous neoplasm treated with cholangioscopy-guided radiofrequency ablation. ACG Case Rep J 2016; 3: 202 - 204

\section{Bibliography}

DOI https://doi.org/10.1055/s-0043-121459

Published online: 23.11.2017

Endoscopy 2018; 50: 176-177

(c) Georg Thieme Verlag KG

Stuttgart · New York

ISSN 0013-726X

\section{ENDOSCOPY E-VIDEOS}

https://eref.thieme.de/e-videos

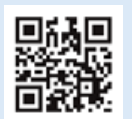

Endoscopy E-Videos is a free access online section, reporting on interesting cases and new techniques in gastroenterological endoscopy. All papers include a high quality video and all contributions are freely accessible online.

This section has its own submission website at https://mc.manuscriptcentral.com/e-videos 